\title{
Uji Stabilitas Tanah Ekspansif Menggunakan Penambahan Limbah Bata Ringan Pada Jalan Tamanan Kabupaten Nganjuk
}

\section{Expansive Soil Stability Test Using Addition of Lightweight Brick Waste to Tanjanan Road, Nganjuk Regency}

\author{
Mochammad Dermawan Adi Laksono', Ahmad Ridwan², Yosef Cahyo ${ }^{3}$, Dwifi Aprillia \\ Karisma $^{4}$ \\ ${ }^{1}$ Jurusan Teknik Sipil, Fakultas Teknik, Universitas Kadiri, Jl. Selomangleng 1 Kediri Indonesia. Email : \\ dermawanadi292@gmail.com \\ ${ }^{2}$ Jurusan Teknik Sipil, Fakultas Teknik, Universitas Kadiri, Jl. Selomangleng 1 Kediri Indonesia. Email : \\ ahmad_ridwan@unik-kediri.ac.id \\ ${ }^{3}$ Jurusan Teknik Sipil, Fakultas Teknik, Universitas Kadiri, Jl. Selomangleng 1 Kediri Indonesia. Email : \\ yosef_cahyo@unik-kediri.ac.id \\ ${ }^{4}$ Jurusan Teknik Sipil, Fakultas Teknik, Universitas Kadiri, Jl. Selomangleng 1 Kediri Indonesia. Email : \\ dwifiaprilliakarisma@gmail.com
}

\begin{abstract}
Abstrak
Tumpuan pertama sebuah pekerjaan teknik sipil adalah tanah. Indonesia memiliki beragam tanah salah satunya dalah tanah ekspansif seperti yang terletak pada Jalan Tamanan Kab Nganjuk. Salah satu cara untuk menanggulangi daya dukung tanah yang rendah menggunakan stabilitas tanah. Penambahan yang digunakan dengan variasi 5\% 10\% 15\% 20\%. Penelitian ini bertujuan mengetahui partikel yang terdapat pada tanah, Mengetahui hasil optimum pada batas stabilitas tanah dan pemadatan. Mengetahui sifat fisis pada tanah tersebut dengan penambahan bata ringan meliputi pengujian kadar air berat jenis, batas konsistensi, dan pemadatan dengan uji proktor. Hasil dalam penelian tanah tersebut termasuk dalam aktivitas tanah monmorilite dan setelah dilakukan penambahan limbah bata ringan. Dengan maximum 20\% dari berat kering benda uji. Nilai Liquid Limitnya turun menjadi 46,43\% dan Nilai Plastis Limit menurun menjadi 35,21\%, Sehingga Indek Plastis mengalami penurunan menjadi 11,22\%. Pada Uji Proktor benda uji struktur tanah asli memiliki berat volume kering sebesar 8\%,5\% dihasilkan 9,27gr, 10 dihasilkan 10,4gr ,15 dihasilkan 10,42gr.dan 10 dihasilkan 9,9gr. Demikian dapat disimpulkan stabilitas tanah ekspansif dengan penambahan limbah bata ringan adalan $15 \%$ cukup baik. Dengan variasi penambahan 20\% mengalami penurunan.
\end{abstract}

Kata Kunci: Stabilitas tanah; tanah ekspansif; bata ringan

\begin{abstract}
The first foundation of a civil engineering work is land. One way to overcome the low soil carrying capacity is using soil stability. Additions are used with variations of 5\%,10\%,15\%,20\%. This study aims to determine the particles contained in the soil, find out the optimum results in the soil stability and compaction limits. Knowing the physical properties of the soil with the addition of lightweight bricks includes testing the specific gravity water content, consistency limits, and compaction with the test of the actor. The results of the study are included in the monmorilite soil activity and after the addition of light brick waste. With a maximum of 20\% of the dry weight of the test specimen. The value of its Liquid Limit decreased to 46.43\% and the Plastic Limit Value decreased to $35.21 \%$, so the Plastic Index decreased to $11.22 \%$. In the Actor Test, the original soil structure test specimen has a dry volume weight of $8 \%, 5 \%$ is produced $9.27 \mathrm{gr}, 10$ is generated $10.4 \mathrm{gr}, 15$ is $10.42 \mathrm{gr}$ and 10 is 9.9gr. Thus it can be concluded that the stability of expansive soils with the addition of light brick waste is $15 \%$ good enough. With a variation of an additional $20 \%$ decreased.
\end{abstract}

Keywords: Soil stability; expansive soil; light brick 


\section{PENDAHULUAN}

Sebuah tumpuan pada pekerjaan konstruksi yang sangat menentukan sebuah pekerjaan adalah tanah, tanah menjadi suatu dasar dalam semua pekerjan konstruksi. Pertimbangan yang perlu difikirkan pertama kali dalam sebuah pekerjan beberapa jenis tanah memiliki kualitas, sifat yang memiliki dayadukung tanah yang rendah dan suatu saat akan memiliki dampak pada konstruksi tersebut. Untuk itu dalam sebuah perencanaan konstruksi hal terpenting seperti tanah perlu ada penyelidikan khusus karakter yang menopang sebuah bangunan diatasnya seperti gedung atau pekerjaan lainnya. Beberapa tanah yang memiliki daya dukung yang rendah salah satunya adalah tanah lempung ekspansif. Tanah dengan kadar air terlalu tinggi dan sebaliknya rendah disebut tanah ekspansif. Untuk itu tanah jenis ini memiliki perlakuan tersendiri untuk menjadi sebuah penopang sebuah konstruksi.

Stabilitas tanah adalah menjadi jalan keluar dalam menanggulangi masalah tersebut, dalam sistem klasifikasinya tanah dikelompokkan kedalam butiran kasar dan halus. Tanah berbutir halus dibagi menjadi 2 (dua) jenis yaitu tanah lempung kohesif dan non kohesif.Indonesia adalah sebuah Negara yang memiliki dua musim yaitu musim kemarau dan musim penghujan.Pengambilan bahan uji ini terletak di jalan tamanan yang berapa di Nganjuk. Tanah di daerah tersebut sangat rentan terhadap potensi terjadinya bertambah danberkurangnya kadar air dalam sebuah tanah. Jika musim hujan tanah rentan terjadi pengembangan tanah (swelling), kadar air terlalu tinggi dapat menyebabkan daya dukung tanah yang terlalu rendah dan kuat gesernya rendah, namun pada musim kemarau tanah rentan mengalami penyusutan air yang rendah, daya dukung tinggi dan kuat gesernya tinggi. Untuk mengatasi masalah tersebut perlu dilakukan stabilitas tanah agar menjadi stabill dan aman untuk didirikan konstruksi diatasnya

\section{METODE PENELITIAN}

Tanah yang dipakai adalah tanah yang berada di daerah Desa Gemenggeng Kecamatan Bagor Kabupaten Nganjuk.Bahan yang akan ditambahkan dalam penelitian ini adalah limbah bata ringan yang tidak terpakai. Bata Ringan dari bekas bangunan yang tidak terpakai.Bata Ringan tesebut diperoleh dari limbah bata ringan yang tidak terpakai karena pecah saat packing/ pengiriman. Air yang dipergunakan dalam penelitian ini dari Fakultas Teknik, Universitas Kadiri, Kediri pada uji Metode yang digunakan dalam kesimpulan sebagai berikut:
Studi literatur dan Metode observasi dan pengumpulan data teknis. Pengumpulan data-data sebagai teknis penelitan sebagai berikut: tanah pada lokasi penelitian guna sampling dan mengetahui kondisi sebenarnya pada lapangan. Data stabilisasi struktur tanah serta data yang di peroleh sesuai dengan kondisi di lapangan.

Dalam proses penelitian yang berjudul "Stabilitas Tanah Ekspansif Menggunakan Penambahan Limbah Bata Ringan Pada Jalan Tamanan Kabupaten Nganjuk" ini penulis menggunakan metode penelitian yang menggunakan metode penambahan pencampurannya atau dengan mixing. Model penambahan yang digunakan variasi pencampuran tanah ekspansif dengan limbah Bata Ringan. Daya dukung tanah meningkat seiring dengan meningkatnya konsentrasi penambahan limbah Bata Ringan. Konsentrasi campuran limbah Bata Ringan ditetapkan pada nilai $0 \%, 5 \%, 10 \%$, $15 \%, 20 \%$. Limbah Bata Ringan yang akan dipergunakan sebagai formula penelitian. lalu bahan yang sudah disiapkan dengan melakukan pencampuran dengan berat benda uji. Dilanjutkan dengan pengujian berat isi, konsistensi tanah, dan kepadatan tanah. Setelah pengujian selesai hasil yang didapatkan dianalisa dan didapatkan kesimpulan.

Pengambilan sampel tanah di sekitar bahu jalan Tamanan Kabupaten Nganjuk diawali dengan pengumpulan bata ringan yang diambil dari sisa proyek-proyek bangunan gedung. Uji sifat fisik tanah antara lain kadar air dan analisis gradasi butiran merupakan langkah lanjutannya. Setelah itu pengujian limbah bata ringan tentang unsur-unsur yang ada didalamnya. Untuk mengetahui berat benda dilakukan penimbangan tanah lempung dengan presentase $100 \%, 95 \%, 90 \%, 85 \%, 80 \%$. Pencampuran tanah + limbah bata ringan sesuai dengan berat benda uji. Analisis selanjutnya melakukan pengujian berat isi, konsistensi tanah (Atterbag Limit), kepadatan tanah (Proctor). Sehingga dapat menyimpulkan hasil analisis olahan data sebagai pertimbangan selanjutnya.

Alur Penelitian diatas dapat dijelaskan sebagai berikut : 


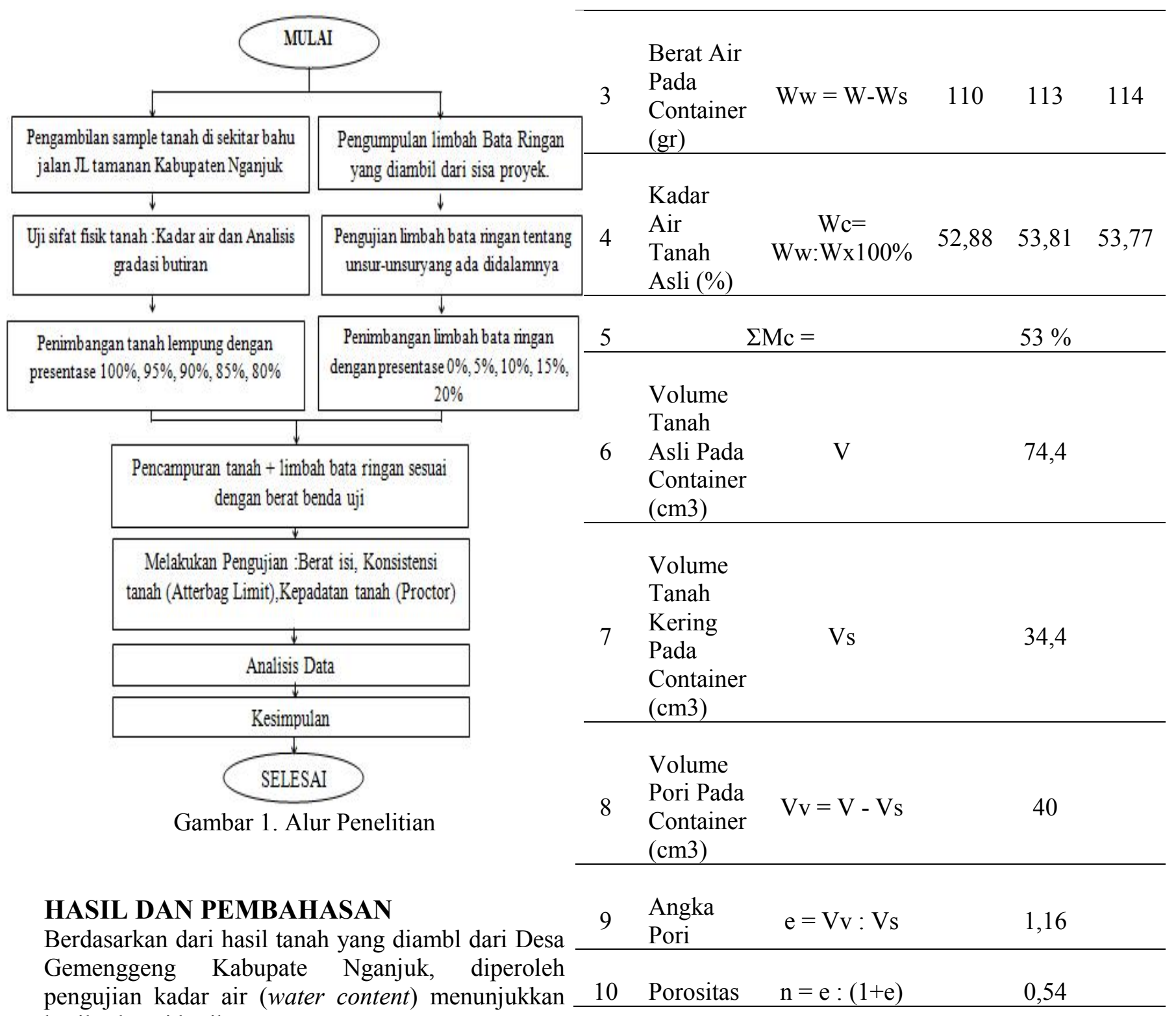

hasil sebagai berikut :

Tabel 1. Pengujian Kadar Air (Water Content)

No. Uji Rumus

Sampel

$1 \quad 2 \quad 3$

Berat

Tanah

1 Asli Pada

Container

(gr)

Berat

Tanah

2 Kering

Container

(gr)
Dari hasil diatas didapatkan hasil dari uji berat isi pengurangan berat isinya didapatkan dengan uji coba 3 sample dengan rata rata $53 \%$. Dengan $\mathrm{V}=$ $74,4, \mathrm{Vs}=34,4, \mathrm{Vv}=40$, angka pori 1,6 dan porositas 0,54 .

Uji analisis gradasi butir dengan tanah dengan volume $1 \mathrm{~kg}$ dimaksudkan untuk mengetahui klasifikasi struktur tanah yang akan di uji guna disajikan pada tabel 2 berikut. 
Tabel 2. Analisis Gradasi Butir Struktur Tanah Asli

\begin{tabular}{|c|c|c|c|c|}
\hline \multirow{2}{*}{\multicolumn{2}{|c|}{ Jenis Partikel }} & \multirow{3}{*}{$\begin{array}{c}\text { Diamater } \\
(\mathrm{mm})\end{array}$} & \multicolumn{2}{|c|}{ Jumlah } \\
\hline & & & (gr) & $(\%)$ \\
\hline \multirow{4}{*}{$\begin{array}{c}\text { KERIKIL } \\
\text { (Gravel) }\end{array}$} & Builders & & \multirow{4}{*}{0} & \multirow{4}{*}{0} \\
\hline & Cobbles & $64-256$ & & \\
\hline & Pebbless & $4-64$ & & \\
\hline & $\begin{array}{l}\text { Granule } \\
\mathrm{s}\end{array}$ & $2-4$ & & \\
\hline \multirow{5}{*}{$\begin{array}{l}\text { PASIR } \\
\text { (Sand) }\end{array}$} & $\begin{array}{l}\text { Very } \\
\text { coarse } \\
\text { sand }\end{array}$ & $1-2$ & 13 & 1,3 \\
\hline & $\begin{array}{l}\text { Coarse } \\
\text { sand }\end{array}$ & $0,5-1$ & 26 & 2,6 \\
\hline & $\begin{array}{l}\text { Medium } \\
\text { sand }\end{array}$ & $0,25-0,5$ & 23 & 2,3 \\
\hline & $\begin{array}{l}\text { Fine } \\
\text { Sand }\end{array}$ & $\begin{array}{c}0,125- \\
0,25\end{array}$ & 16 & 1,6 \\
\hline & $\begin{array}{l}\text { Very } \\
\text { fine } \\
\text { Sand }\end{array}$ & $\begin{array}{c}0,0625- \\
0,125\end{array}$ & 43 & 4,3 \\
\hline \multicolumn{2}{|c|}{ LANAU (Silt) } & $\begin{array}{l}0,002- \\
0,0624\end{array}$ & 534 & $\begin{array}{c}53 \\
4\end{array}$ \\
\hline \multicolumn{2}{|c|}{ LEMPUNG (Clay) } & $\begin{array}{c}<0,002 \\
(\mathrm{MICRO})\end{array}$ & 345 & $\begin{array}{c}34 \\
5\end{array}$ \\
\hline \multicolumn{3}{|c|}{ OTAL } & 1000 & 100 \\
\hline
\end{tabular}

Tabel diatas merupakan Hasil Analisis Uji Gradasi Butir di Laboratorium Teknik Sipil Universitas Kadiri Uji analisis gradasi butir dengan tanah dengan volume $1 \mathrm{~kg}$ dimaksudkan untuk mengetahui klasifikasi struktur tanah yang akan di uji guna perhitungan lebih lanjut lagi.

Karakteristik limbah limbah bata ringan yang dipergunakan pada penelitian berikut menunjukkan nilai kadar air kering udara 5,38\%, berat jenis Limbah limbah bata ringan 1,83 gr/cm3dengan indeks plastisitas 0 (non plastis).

Uji berat isi dilakukan pada tanah yang dicampur dengan limbah bata ringan dengan nilai penambahan sebesar $0 \%, 5 \%, 10 \%, 15 \%$ dan $20 \%$ dari seluruh berat kering benda uji tanpa pemeraman. Hasil pemeriksaan telah dirangkum dalam tabel 3 berikut:

Tabel 3. Berat Isi Tanah Limbah Bata

\begin{tabular}{cc}
\hline Kadar Bata Ringan & Berat Jenis \\
\hline 0 & 2,37 \\
5 & 2,44 \\
10 & 2,51 \\
15 & 2,55 \\
20 & 2,66
\end{tabular}

Sumber :Hasil Analisis Berat Isi di Laboratorium Teknik Sipil Universitas Kadiri

Hasil dari batas konsistensi tertinggi liquid limit dan plastis limit dengan pencampuran $0 \%, 5 \%, 10 \%$, $15 \%, 20 \%$ limbah bata ringan sebagai campuran tanah ekspansif.

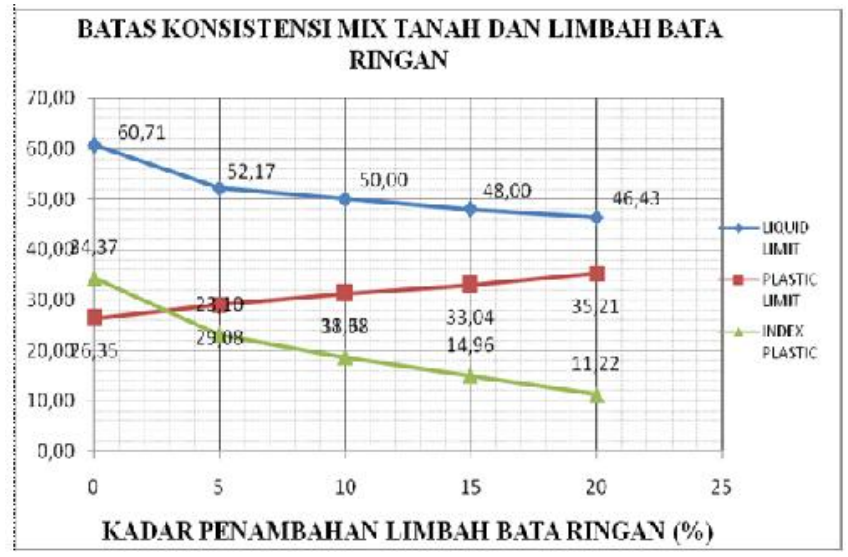

Gambar 2. Grafik Batas Konsistensi

Dari penelitian dan perhitungan diatas, Pada gambar 2 tentang garifk batas konsistensi. Indeks plastisitas benda uji dengan penambahan $0 \%$ limbah Bata Ringan (Tanah Asli) memiliki persentase sejumlah $34,37 \%$ dan persentase fraksi gradasi tanah kurang dari $0,002 \mathrm{~mm}$ sebesar $34,5 \%$, maka sampel tanah yang diambil langsung dari sekitar jalan tamanan kab nganjuk yang bertepat di desa gemenggeng (Tanah asli titik kasus kerusakan lapisan tanah) memiliki nilai aktivitas 34,37 : 34,2 = 1,04 yang disimpulkan bahwa masuk kedalam ketegori jenis mineral lempung Montmorillonite. 


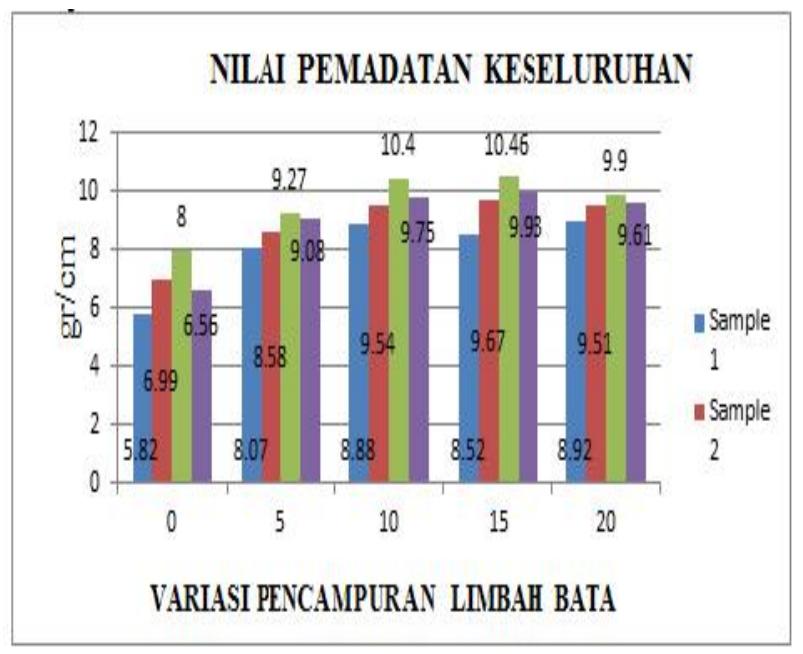

Gambar 3. Grafik Hasil Uji Kepadatan Tanah dari Keseluruhan Benda Uji

Pada gambar 3 diatas mengenai grafik hasil uji kepadatan tanah dari keseluruhan benda uji, Struktur Tanah Asli setelah dilakukan uji pemadatan sebesar $8 \mathrm{gr} / \mathrm{cm} 3$. Penambahan Limbah bata ringan sebanyak $5 \%$ berat volume kering 9,27 $\mathrm{gr} / \mathrm{cm} 3,10 \%$ adalah $10,4 \mathrm{gr} / \mathrm{cm} 3,15 \%$ adalah 10,42 $\mathrm{gr} / \mathrm{cm} 3 \mathrm{dan}$ penambahan limbah bata ringan $20 \%$ berat volume kering $9,9 \mathrm{gr} / \mathrm{cm} 3$.

\section{KESIMPULAN}

Menurut teori dalam tanah yang diambil pada daerah Jalan Tamanan yang tepatnya berada di Desa Gemenggeng KecamatanBagor KabupatenNganjuk termasuk kedalam kategori aktivitas Monmoroillonite. Struktur mineral Monmoroillonite mempunyai kepekaan terhadap pengaruh resapan air,dengan demikian menjadikannya sangat mudah mengembang ketika terkena air. Karena sifat tersebut, struktur mineral tanah Monmorillonite sangat sering menimbulkan masalah pada bangunan, seperti dapat merusak struktur ringan dan perkerasan jalan raya.

Nilai optimum yang didapatkan pada stabilitas tanah dengan penambahan bata ringan variasi $0 \%$, $5 \%, \quad 10 \%, \quad 15 \% \quad 20 \%$ memiliki nilai optimum dengan nilai $110 \%$ dengan hasil 60,71 , nilai PL $20 \%$ dengan hasil 33,21 dan IP $0 \%$ dengan hasil 34,37

Nilai optimum yang didapatkan pada uji pemadatan dengan penambahan bata ringan variasi $0 \%, 5 \%$, $10 \%, 15 \% \quad 20 \%$ memiliki nilai optimum dengan variasi pencampuran $15 \%$ dengan

Saran-saran yang dapat penyusun utarakan guna tercipta keselarasan kebutuhan adalah pengaplikasian kegiatan dalam penelitian berikut guna menanggulangi kasus permasalahan kerusakan lapisan tanah pada setiap titik area maupun lokasi, struktur tanah dan kebutuhan lapangan berbedabeda.

\section{REFERENSI}

I. Ngurah Wardana. 2009. "Kelakuan Tanah Dengan Sifat Kembang-Susut Yang Tinggi Pada Stabilisasi Tanah Dengan Bahan Serbuk Marmer Dan Bahan Stabilia”. J. Ilm. Tek. Sipil, vol. 13, no. 2.

B. M. Das. 1988. "Mekanika Tanah Rekayasa Geoteknis". Institut Teknologi 10 Nopember.

S. A. Dwi Sabda Budi Prasetya1, Seto Priyambodo2. 2008. "Pengolahan Emas Tradisional Di Propinsi Ntb”. vol. 4, no. 2, pp. 91-93.

T. R. Raswitaningrum and Juliayatna. 2017. "Penambahan Semen Dan Abu Sekam Padi Untuk (American Association of State Higway" no. November, pp. 1-2.

A. I. Candra. 2017. "Analisis Daya Dukung Pondasi Strauss Pile Pada Pembangunan Gedung Mini Hospital Universitas Kadiri”. Ukarst, vol. 1, no. 1, pp. 63-70.

I. Adha. 2017. "Pengaruh durabilitas terhadap daya dukung stabilisasi tanah menggunakan lempung plastisitas rendah dengan kapur". no. 1.

A. I. Candra, E. Gardjito, Y. Cahyo, and G. A. Prasetyo. 2019. "Pemanfaatan Limbah Puntung Rokok Filter Sebagai Bahan Campuran Beton Ringan Berpori”. UKaRsT, vol. 3, no. 1, p. 82.

S. Himawan. 2018. "Stabilisasi Tanah Lempung Menggunakan Gypsum, Kapur ( $\mathrm{CaO}$ ) dan Semen Ditinjau dari Nilai CBR ( California Bearing Ratio).

A. Andriani, R. Yuliet, and F. L. 2012. Fernandez, "Pengaruh Penggunaan Semen Sebagai Bahan Stabilisasi Pada Tanah Lempung Daerah Lambung Bukit Terhadap Nilai Cbr Tanah”. J. Rekayasa Sipil, vol. 8, no. 1, p. 29.

Karl Tarzaghi and Ralph b. 1994. "Mekanika Tanah Dalam Praktik Rekayasa”.

I. Widiantoro and F. Ahmad. 2017. "G-SMART: Jurnal Teknik Sipil Unika Soegijapranata Volume 1 | Nomor 1 | 2017," pp. 33-42.

A. D. Cahyo. 2016. "Perbandingan Biaya Dan Waktu Pada Pelaksanaan Pekerjaan Pasangan Dinding Bata Ringan Dan Dinding Bata Merah Dengan Metode Time Study”. J. Sains dan Teknol. Utama, vol. XI.

A. I. Candra. 2018. "Studi Kasus Stabilitas Struktur Tanah Lempung Pada Jalan Totok Kerot Proteksi/Juni 2020 Volume 2 No. 1 
Kediri Menggunakan Limbah Kertas". UKaRsT, vol. 2, no. 2, p. 11.

F. R. Yamali. 2016. "Analisa Energi Alat Pemadat Tanah Lempung Dilapangan”. J. Civronlit Unbari, vol. 1, no. 1, p. 33. 